Research Article

\title{
Rosmarinic Acid Alleviates the Endothelial Dysfunction Induced by Hydrogen Peroxide in Rat Aortic Rings via Activation of AMPK
}

\author{
Hui Zhou, ${ }^{1}$ Baocai Fu, ${ }^{2}$ Bo Xu, ${ }^{1}$ Xiangquan Mi, ${ }^{3}$ Gang Li, ${ }^{1}$ Chengjun Ma, ${ }^{1}$ Jianxin Xie, ${ }^{3}$ \\ Ji Li, ${ }^{1}$ and Zhenhua Wang ${ }^{1}$ \\ ${ }^{1}$ Center for Mitochondria and Healthy Aging, College of Life Sciences, Yantai University, Yantai 264005, China \\ ${ }^{2}$ Intensive Care Unit, Yantaishan Hospital, Yantai 264001, China \\ ${ }^{3}$ School of Medicine, Shihezi University, Shihezi 832002, China
}

Correspondence should be addressed to Ji Li; lijimelissafang@yahoo.com and Zhenhua Wang; zhenhuawang@tom.com

Received 7 April 2017; Revised 9 June 2017; Accepted 20 June 2017; Published 13 August 2017

Academic Editor: Jie Li

Copyright (C) 2017 Hui Zhou et al. This is an open access article distributed under the Creative Commons Attribution License, which permits unrestricted use, distribution, and reproduction in any medium, provided the original work is properly cited.

\begin{abstract}
Endothelial dysfunction is the key player in the development and progression of vascular events. Oxidative stress is involved in endothelial injury. Rosmarinic acid (RA) is a natural polyphenol with antioxidative, antiapoptotic, and anti-inflammatory properties. The present study investigates the protective effect of RA on endothelial dysfunction induced by hydrogen peroxide $\left(\mathrm{H}_{2} \mathrm{O}_{2}\right)$. Compared with endothelium-denuded aortic rings, the endothelium significantly alleviated the decrease of vasoconstrictive reactivity to $\mathrm{PE}$ and $\mathrm{KCl}$ induced by $\mathrm{H}_{2} \mathrm{O}_{2} \cdot \mathrm{H}_{2} \mathrm{O}_{2}$ pretreatment significantly injured the vasodilative reactivity to $\mathrm{ACh}$ in endothelium-intact aortic rings in a concentration-dependent manner. RA individual pretreatment had no obvious effect on the vasoconstrictive reaction to $\mathrm{PE}$ and $\mathrm{KCl}$, while its cotreatment obviously mitigated the endothelium-dependent relaxation impairments and the oxidative stress induced by $\mathrm{H}_{2} \mathrm{O}_{2}$. The RA cotreatment reversed the downregulation of AMPK and eNOS phosphorylation induced by $\mathrm{H}_{2} \mathrm{O}_{2}$ in HAEC cells. The pretreatment with the inhibitors of AMPK (compound C) and eNOS (L-NAME) wiped off RA's beneficial effects. All these results demonstrated that RA attenuated the endothelial dysfunction induced by oxidative stress by activating the AMPK/eNOS pathway.
\end{abstract}

\section{Introduction}

The vascular endothelium plays critical roles in maintaining the vascular structure and function [1]. In physiological states, the endothelium releases both relaxing and contracting factors including nitric oxide (NO), prostacyclin, and endothelin, which contribute to the local regulation of vascular tone and the coagulation [2].

Endothelial cells also secrete the reactive oxygen species (ROS), especially the hydrogen peroxide $\left(\mathrm{H}_{2} \mathrm{O}_{2}\right)$, as the fast diffusion signal to recruit the leukocytes to the injury site and the endothelial NADPH oxidase is the main source of ROS [3]. Whereas excess ROS will result in oxidative stress which contributes to vascular dysfunction in cardiovascular events [4], diabetes [5], stroke [6], atherosclerosis [7], and so forth, it is becoming increasingly clear that oxidative stress contributed to the development of the macrovascular complications [8]. Indeed, recent studies have shown that the mechanism of endothelial dysfunction is largely due to the reduced bioavailability of endothelium-derived NO by oxidative stress [9]. The presence of ROS not only reduces the bioavailability of NO [10] but also results in the eNOS uncoupling which will result in more ROS formation [11].

Accumulating evidences from bench to bed support the free radical scavenging properties of phenolic antioxidants and the pharmacological activities against oxidative stressmediated vascular disorders. Such (cases?) as resveratrol [12], curcumin [13], and the flavanol (-)-epicatechin [14] showed widely protective effects on the endothelial cells 
in vivo and in vitro. Rosmarinic acid is one of the most potent antioxidants among the simple phenolic compounds [15]. Rosmarinic acid ( $\alpha$-O-caffeoyl-3, 4-dihydroxyphenyl lactic acid; RA) is a natural phenol antioxidant contained in some Labiatae family plants used in traditional medicine and phytotherapy such as Perilla frutescens (L.) Britt., Salvia miltiorrhiza Bge., Rosmarinus officinalis L., and Lavandula angustifolia Mill. RA possesses many bioactivities including antioxidative, astringent, anti-inflammatory, antimicrobial, antiangiogenic, antiviral, antirheumatic, antiallergic, antidepressant, antidiabetic, and antitumor effects [16]. Sotnikova et al. proved that RA improved the reactivity to phenylephrine of aortic rings and prevented the upregulation of IL- $1 \beta$, $\mathrm{TNF}-\alpha$, and endothelin pathway in diabetic rats in vivo [8], while the effects on endothelium-dependent vasodilation were not investigated. Here, we established an oxidative injury with hydrogen peroxide $\left(\mathrm{H}_{2} \mathrm{O}_{2}\right)$ and investigated the protective effects of RA on endothelium-dependent vasodilation mediated by acetylcholine (ACh) and the underlying mechanisms. Our results demonstrated that the protective activities of RA are mediated by an AMPK-eNOS signaling pathway.

\section{Materials and Methods}

2.1. Chemicals. Rosmarinic acid, acetylcholine (ACh), compound C,5-aminoimidazole-4-carboxamide- $1-\beta$-D-ribofuranoside (AICAR), apocynin, and diphenyliodonium were purchased from Sigma Chemical Co. (St. Louis, MO, USA); phenylephrine (PE) and $l$-N-nitro arginine methyl ester (L-NAME) were purchased from Aladdin Industrial Co. (Shanghai, China). The other reagents were of analytical purity.

2.2. Animals. Three-month-aged male Wistar rats (200$250 \mathrm{~g}$ ) were obtained from the Animal Center of Shandong Luye Pharmaceutical Co. Ltd. (Yantai, China). The rats were maintained in a $12 \mathrm{~h}$ light/dark cycle and had free access to food and water. All experimental procedures were approved by the Institutional Animal Care and Use Committee of National Institute of Pharmaceutical Education and Research.

2.3. Preparation of Rat Aortic Rings. The thoracic aorta was isolated and placed in $4^{\circ} \mathrm{C}$ modified Krebs-Henseleit $(\mathrm{K}-\mathrm{H})$ solution (mM: $\mathrm{NaCl}, 118 ; \mathrm{KCl}, 4.7 ; \mathrm{KH}_{2} \mathrm{PO}_{4}, 1.2 ; \mathrm{MgSO}_{4}$, 1.2; $\mathrm{NaHCO}_{3}, 25.0 ; \mathrm{CaCl}_{2}, 2.5 ; \mathrm{D}$-glucose, 10.0. $\mathrm{pH} 7.4$, [17]). The excess connective tissue was carefully cleaned and the aorta was cut into segments approximately $3 \mathrm{~mm}$ long. In some experiments, the aortic endothelium was removed by the paper clip. The tension of the aortic ring was recorded with a linear force transducer, and the $\mathrm{K}-\mathrm{H}$ solution was aired with a $95 \% \mathrm{O}_{2}$ and $5 \% \mathrm{CO}_{2}$ mixture and maintained at $37^{\circ} \mathrm{C}$. All the vessels were equilibrated for $1 \mathrm{~h}$ and the basic tension was adjusted to $2.0 \mathrm{~g}$ before the experiment. During the equilibration period, the K-H solution was replaced every $15 \mathrm{~min}$. At the beginning of an experiment, the aortic rings were exposed to $80 \mathrm{mM} \mathrm{KCl}$ for 3 times until the responses were stable. The intact endothelium function was verified by the relaxation reaching more than $85 \%$ induced by ACh $(10 \mu \mathrm{M})$ to induce in the precontracted aorta rings with $\mathrm{PE}(1 \mu \mathrm{M})$. The endothelium was considered effectively removed when the relaxation was less than $10 \%$ induced by ACh.

2.4. Endothelial Dysfunction Induced by $\mathrm{H}_{2} \mathrm{O}_{2}$ and the $\mathrm{RA}$ Treatment in Rat Aortic Rings. After $10 \mathrm{~min}$ equilibration with the new $\mathrm{K}-\mathrm{H}$ solution, the aortic rings were pretreated with various concentrations of $\mathrm{H}_{2} \mathrm{O}_{2}(2.5,5.0$, and $10.0 \mathrm{mM}$ ) for $10 \mathrm{~min}$. Following washout of $\mathrm{H}_{2} \mathrm{O}_{2}$, the aortic rings were depolarized with $80 \mathrm{mM} \mathrm{KCl}$ for 2 times. After returning to baseline tension, the rings were allowed to equilibrate for $20 \mathrm{~min}$, and then the contraction were induced with $\mathrm{PE}(1 \mu \mathrm{M})$ till a stable plateau in tension. Then, each ring was exposed to increasing concentration of ACh $\left(10^{-3}, 10^{-2}, 10^{-1}\right.$, $1,5,10,50 \mu \mathrm{M})$ to generate a dose-dependent relaxation response. In the RA intervention experiment, the aortic rings were incubated with various concentrations $(50.0 \mu \mathrm{M}$, $25 \mu \mathrm{M}, 12.5 \mu \mathrm{M})$ of RA $10 \mathrm{~min}$ prior to exposure to $5 \mathrm{mM}$ $\mathrm{H}_{2} \mathrm{O}_{2}$. Thereafter, a second vasodilation reactivity to ACh was obtained to evaluate the integrity of the endothelium after PE-induced contraction. In order to investigate the roles of AMPK in $\mathrm{H}_{2} \mathrm{O}_{2}$-induced endothelium dysfunction, the aortic rings were separately pretreated for $10 \mathrm{~min}$ with AMPK inhibitor (compound $\mathrm{C}$ ) and AMPK activator (AICAR) before the exposure to $\mathrm{H}_{2} \mathrm{O}_{2}(5 \mathrm{mM})$.

2.5. Measurement of $\mathrm{H}_{2} \mathrm{O}_{2}$ Caused the Vasocontraction Impairment Mediated by Smooth Muscle Cells. In order to exclude the vasocontraction impairment mediated by smooth muscle cells injury, the vasoconstriction reactivity to $\mathrm{PE}$ was investigated after $5 \mathrm{mM} \mathrm{H} \mathrm{H}_{2} \mathrm{O}_{2}$ treatment in endothelialintact $(\mathrm{EC}+)$ or endothelial-denuded (EC-) aortic rings.

2.6. Detection of $\mathrm{O}_{2}^{-}$by NBT Reduction Assay. NBT reduction assay was performed as the method described previously [18]. Briefly, the aortic rings were incubated with the $\mathrm{K}-\mathrm{H}$ solution containing $100.0 \mu \mathrm{M}$ NBT for $1 \mathrm{~h}$ after the experiment. Subsequently, the $\mathrm{HCl}(0.5 \mathrm{mM})$ was added to stop the reaction. Then, the aortic rings were washed 3 times with PBS buffer; after they were minced and centrifuged at $20000 \mathrm{~g}$ for $20 \mathrm{~min}$ on the part of the mixture of $40 \mathrm{mg} / \mathrm{L}$ diethylenetriaminepentaacetic acid, which was dissolved into $0.1 \mathrm{M}$ $\mathrm{NaOH}$ and $0.1 \%$ SDS, the pellet was suspended in $0.5 \mathrm{~mL}$ of pyridine, along with being heated at $80^{\circ} \mathrm{C}$ for $1.5 \mathrm{~h}$ in order to extract formazan. The mixture was experienced a second centrifugation at $10000 \mathrm{~g}$ for $10 \mathrm{~min}$. Optical density (OD) was measured at $540 \mathrm{~nm}$.

2.7. Cell Culture and Treatment. HAEC (human aortic endothelial cells) were purchased from Cell Bank, Shanghai Institutes for Biological Sciences, Chinese Academy of Sciences, Shanghai, and cultured in Dulbecco's Modified Eagle Medium (GIBCO) supplemented with L-glutamine, pyridoxine hydrochloride, $110 \mathrm{mg} / \mathrm{L}$ sodium pyruvate, $100 \mathrm{U} / \mathrm{mL}$ penicillin, and $100 \mu \mathrm{g} / \mathrm{mL}$ streptomycin and amphotericin at $37^{\circ} \mathrm{C}$ in a humidified atmosphere of $5 \% \mathrm{CO}_{2}$. Cells cultured up to six or fewer passages were first grown to confluence before exposure to $\mathrm{H}_{2} \mathrm{O}_{2}(5 \mathrm{mM})$ for $10 \mathrm{~min}$, and stimulated 


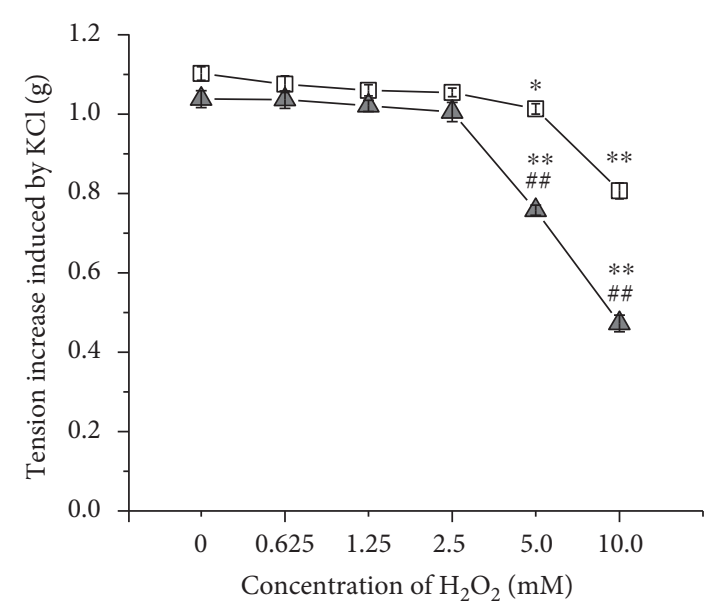

$-\square-E+$
$-\triangle-E-$

(a)

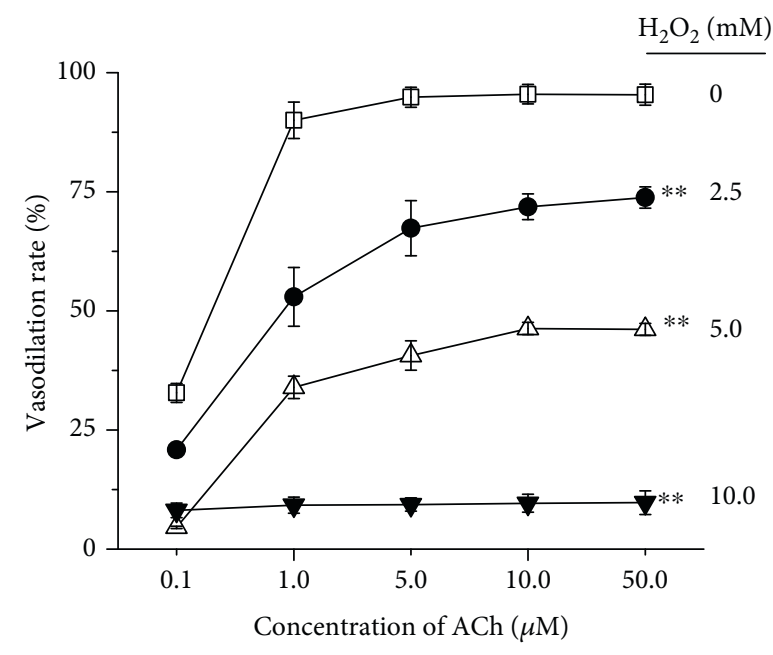

(c)

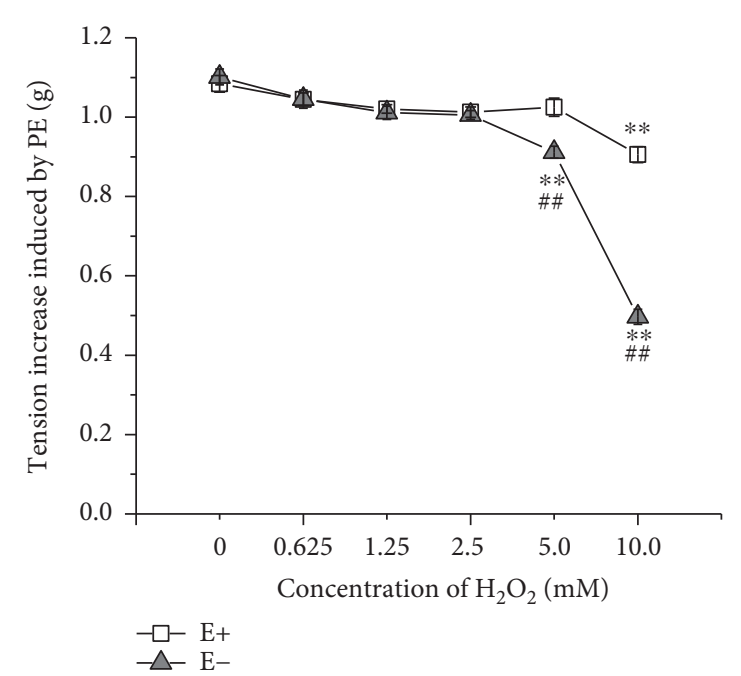

(b)

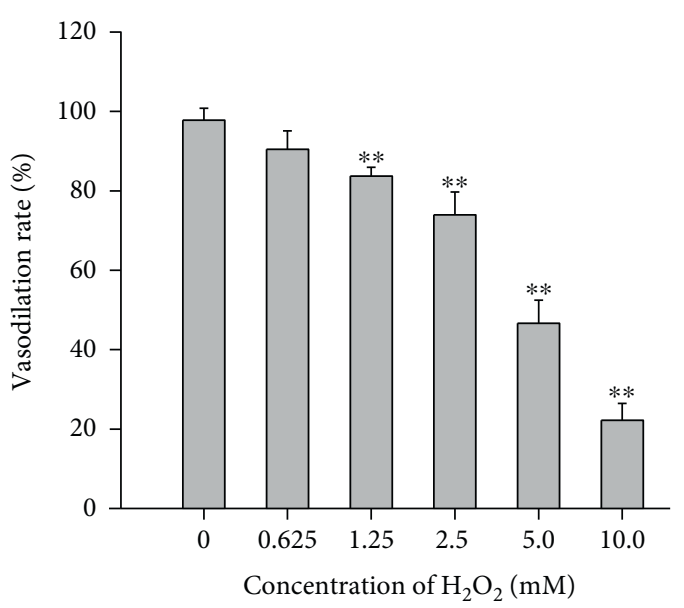

(d)

FIGURE 1: Effects of $\mathrm{H}_{2} \mathrm{O}_{2}$ exposure on PE- and $\mathrm{KCl}$-induced contraction in rat aortic rings. (a) $\mathrm{KCl}$ induced contractile response in $\mathrm{H}_{2} \mathrm{O}_{2}$ treated aortic rings with (E+) or without (E-) endothelium. (b) $\mathrm{PE}$ induced contractile response in $\mathrm{H}_{2} \mathrm{O}_{2}$-treated aortic rings with (E+) or without (E-) endothelium. (c) ACh induced vasodilative response in $\mathrm{H}_{2} \mathrm{O}_{2}$-treated rat aorta with intact endothelium. (d) 5.0 mM $\mathrm{H}_{2} \mathrm{O}_{2}$ pulse treatment $(10 \mathrm{~min})$ induced the endothelium-dependent vasodilation impairments in rat aortic rings with intact endothelium. Data represents as means \pm SD $(n=6)$. (a and b) ${ }^{*} P<0.05,{ }^{* *} P<0.01$ versus the respective untreated group; ${ }^{\# \#} P<0.01$ versus the endotheliumintact aortic rings treated with the same concentration of $\mathrm{H}_{2} \mathrm{O}_{2}$; (c and d) ${ }^{* *} P<001$ versus the untreated group.

by RA $(50 \mu \mathrm{M})$ containing $\mathrm{H}_{2} \mathrm{O}_{2}(5 \mathrm{mM})$ for $10 \mathrm{~min}$, to clarify the activity of AMPK on the expression of the phosphoreNOS. Therefore, cells were treated with compound $\mathrm{C}$ (inhibitor of AMPK) with $\mathrm{H}_{2} \mathrm{O}_{2}$ and in the presence of RA for $10 \mathrm{~min}$.

2.8. Western Blotting Assay. After lysis of the cells, the protein samples $(25 \mu \mathrm{g} /$ lane $)$ were resolved by electrophoresis on $10 \%$ sodium dodecyl sulfate (SDS) polyacrylamide gels and then transferred to nitrocellulose membranes. The membranes were incubated in blocking buffers and then incubated with more of the following primary antibodies: anti-AMPK (1:1000, Cell Signaling Technology, MA, USA), anti-phospho-AMPK (Thr172) (1:1000, Cell Signaling Technology), anti-phospho endothelial nitric oxide synthase (eNOS, Ser1177), and anti-endothelial nitric oxide synthase ( $1: 1000$, Cell Signaling Technology). Thereafter, the membranes were washed and incubated with horseradish peroxidase-conjugated secondary antibodies. (1:2000, Cell Signaling Technology).

2.9. Statistical Analysis. Results were expressed as the mean \pm $\mathrm{SD}$ for separated experiments and statistical analysis were made by paired Student's $t$-test or by one-way ANOVA for multiple factors analysis with SPSS 18.0 software. Differences were considered to be statistically significant when $P<0.05$.

\section{Results}

3.1. Hydrogen Peroxide Exposure Affected the PE- and $\mathrm{KCl}$ Induced Contraction. The cumulative addition of $\mathrm{H}_{2} \mathrm{O}_{2}$ to 


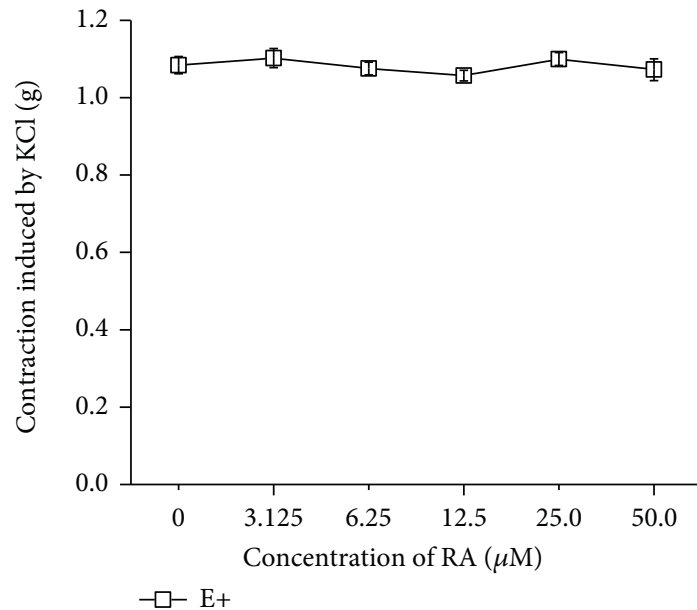

(a)

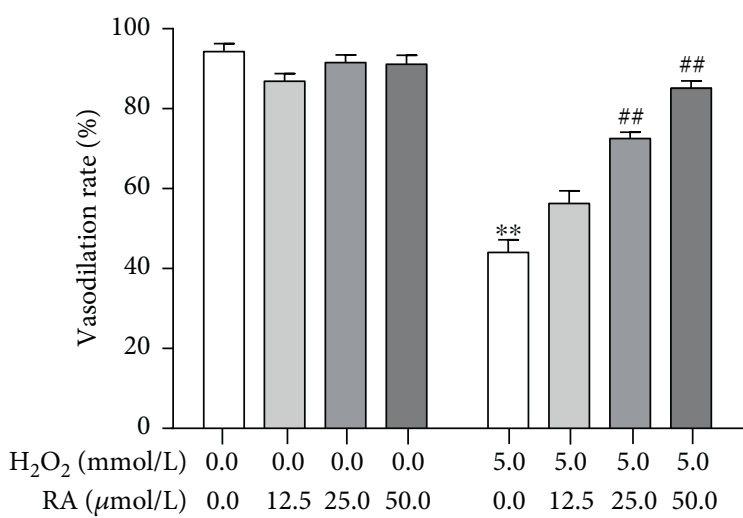

(c)

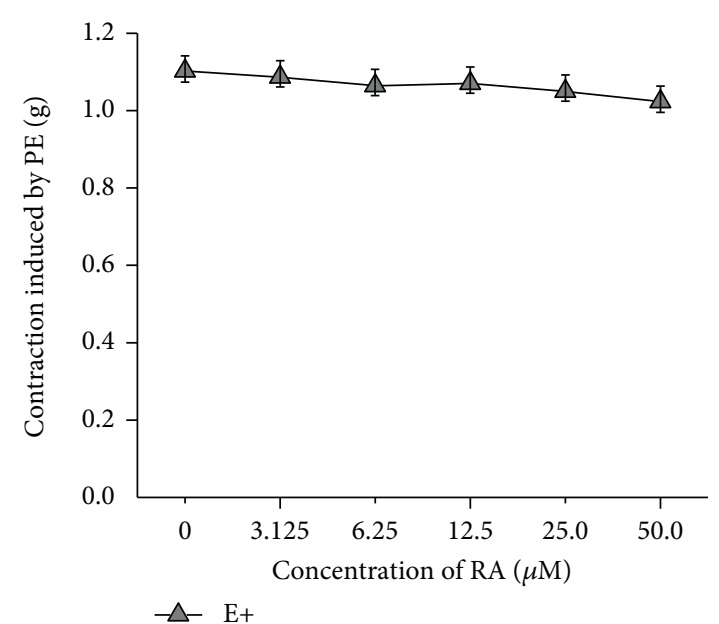

(b)

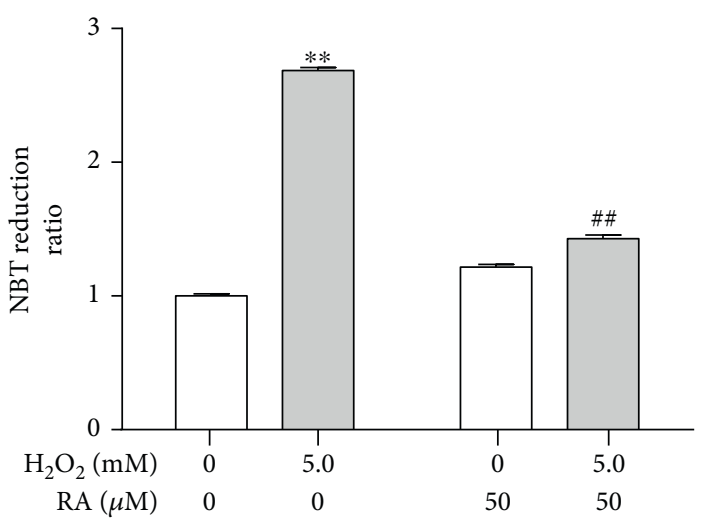

(d)

Figure 2: Rosmarinic acid alleviates the endothelial dysfunction induced by $\mathrm{H}_{2} \mathrm{O}_{2}$ in endothelium-intact rat aortic rings. (a) Rosmarinic acid (RA) pulse exposure showed no effect on the contraction induced by $\mathrm{KCl}$ in rat aortic rings. (b) Rosmarinic acid (RA) pulse exposure showed no effect on the contraction induced by PE in rat aortic rings. (c) Rosmarinic acid (RA) preincubation alleviated the endothelium-dependent vasodilation impairments induced by $\mathrm{H}_{2} \mathrm{O}_{2}$. (d) Rosmarinic acid (RA) cotreatment inhibited the NBT reduction induced by $\mathrm{H}_{2} \mathrm{O}_{2}$ in the endothelium-intact aortic rings. The results were expressed as the means $\pm \mathrm{SD}(n=6) .{ }^{* *} P<0.01$ versus the untreated control group; ${ }^{\# \#} \mathrm{P}<001$ versus the $\mathrm{H}_{2} \mathrm{O}_{2}$-treated group.

10.0 $\mathrm{mM}$ showed no obvious effect on the basal tension in endothelium-intact and endothelium-denuded aortic rings (data were not shown). The contraction response to PE or $\mathrm{KCl}$ was not affected till $\mathrm{H}_{2} \mathrm{O}_{2}$ reached $10.0 \mathrm{mM}$ in endothelium-intact aortic rings. However, the $5.0 \mathrm{mM}$ $\mathrm{H}_{2} \mathrm{O}_{2}$ pretreatment resulted in the significant decrease of the maximum contraction induced by $\mathrm{PE}$ or $\mathrm{KCl}$ in endothelium-denuded aortic rings (Figures 1(a) and 1(b)), which indicated that $\mathrm{H}_{2} \mathrm{O}_{2}$ induced more serious injury to the vascular smooth muscle in the endothelium-denuded aortic rings and the presence of the endothelium alleviated this injury.

A typical model regarding the concentration response curve of $\mathrm{ACh}$-induced endothelium-dependent relaxation was impaired in $\mathrm{H}_{2} \mathrm{O}_{2}$-induced thoracic aorta compared with the control (Figures 1(c) and 1(d)) (control: $\mathrm{pD}_{2}=7.00 \pm 0.05, E_{\max }=90 \% ; 2.5 \mathrm{mM} \mathrm{H}_{2} \mathrm{O}_{2}: \mathrm{pD}_{2}=$ $5.88 \pm 0.12, E_{\max }=73 \% ; 5 \mathrm{mM} \mathrm{H}_{2} \mathrm{O}_{2}: \mathrm{pD}_{2}=4.52 \pm 0.22$, $\left.E_{\max }=47 \%\right)$.
3.2. Effect of $\mathrm{RA}$ on $\mathrm{H}_{2} \mathrm{O}_{2}$-Induced Endothelium-Dependent Vasodilation Impairments in Rat Aortic Rings. The cumulative concentration of RA to $50 \mu \mathrm{M}$ showed no effect on the contraction response to $\mathrm{KCl}$ or PE (Figures 2(a) and 2(b)), and the relaxation response to ACh (Figure 2(c)) in rat aortic rings as well, whereas it significantly alleviated the impairment of vasodilation reaction to ACh induced by $\mathrm{H}_{2} \mathrm{O}_{2}$ in a dose-dependent manner (Figure 2(c)) $(P<0.01)$. Because the oxidative stress mediates the endothelium injury and the NADPH oxidase is the main source of the endogenous reactive oxygen species, the $\mathrm{O}_{2}^{--}$generation in the aortic rings was examined by the NBT reduction. The $5 \mathrm{mM}$ $\mathrm{H}_{2} \mathrm{O}_{2}$ treatment significantly promoted the generation of the reduced NBT (formazan) in isolated rat aortic rings, while the $50 \mu \mathrm{M}$ RA almost entirely abolished the effect of $\mathrm{H}_{2} \mathrm{O}_{2}$ (Figure $2(\mathrm{~d})$ ).

3.3. eNOS Activation Was Involved in the Protection of $R A$ against the Endothelial Dysfunction Induced by $\mathrm{H}_{2} \mathrm{O}_{2}$. Given 


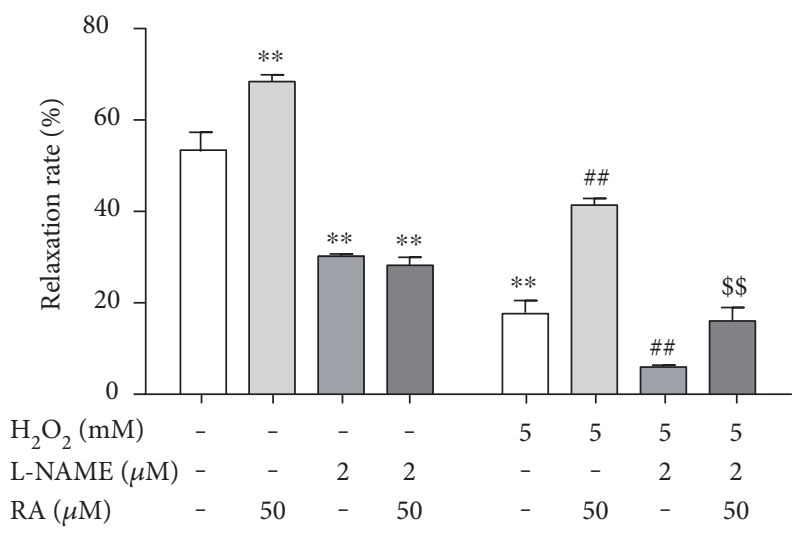

(a)

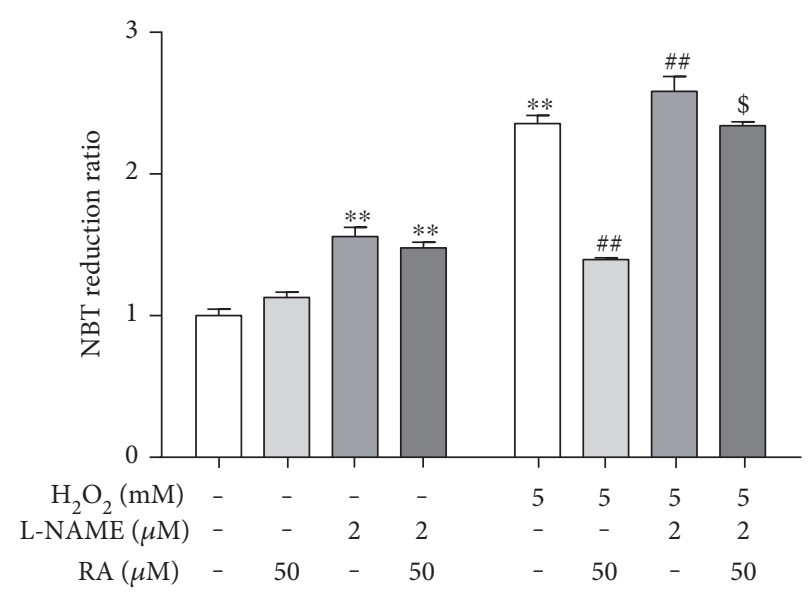

(b)

FIGURE 3: eNOS activation mediated the protection of rosmarinic acid on the endothelial dysfunction induced by $\mathrm{H}_{2} \mathrm{O}_{2}$ in rat aortic rings. The rat aortic rings were cotreated with eNOS inhibitor L-NAME $(2.0 \mu \mathrm{M})$ and RA $(50 \mu \mathrm{M})$ for $10 \mathrm{~min}$, then exposed to $\mathrm{H}_{2} \mathrm{O}_{2}(5.0 \mathrm{mM})$ for another $10 \mathrm{~min}$. The endothelial function was assessed by the endothelium-dependent vasodilation induced by acetylcholine (ACh, $10 \mu \mathrm{M})$ $(n=6)$. (a) The relative endothelium-dependent vasodilation rate after exposure to RA, eNOS inhibitor L-NAME, and $\mathrm{H}_{2} \mathrm{O}_{2}$ in rat aortic rings. (b) The NBT reduction after exposure to RA, eNOS inhibitor L-NAME, and $\mathrm{H}_{2} \mathrm{O}_{2}$ in rat aortic rings. Data are presented as the means \pm SD $(n=6) .{ }^{* *} P<0.01$ versus the untreated control group; ${ }^{\# \#} P<0.01$ versus the $\mathrm{H}_{2} \mathrm{O}_{2}$-treated group; ${ }^{\$} P<0.05$ and ${ }^{\$ \$} P<0.01$ versus the $\mathrm{H}_{2} \mathrm{O}_{2}$ - and RA-cotreated groups, respectively.

that NO is the most potent vasodilator and the modulator of intracellular oxidative status, and it is produced by the eNOS in endothelium [19], we explored the effect of eNOS activation in RA's protection against the endothelial dysfunction induced by $\mathrm{H}_{2} \mathrm{O}_{2}$. The pretreatment with the NOS inhibitor L-NAME alone significantly decreased the vasodilation induced by ACh (Figure 3(a)), while increased the NBT reduction (Figure $3(\mathrm{~b})$ ) in rat aortic rings. The LNAME further increased the vasodilation impairment (Figure 3(a)), whereas it increased the NBT reduction (Figure 3(b)) in rat aortic rings induced by $\mathrm{H}_{2} \mathrm{O}_{2}$. Moreover, the L-NAME treatment abolished the RA's protection on the impairment of the endothelial-dependent relaxation injured by $\mathrm{H}_{2} \mathrm{O}_{2}$ (Figure $3(\mathrm{a})$ ). And the decrease of NBT reduction induced by RA was also reversed by L-NAME in $\mathrm{H}_{2} \mathrm{O}_{2}$ treated aortic rings (Figure 3(b)).

3.4. AMPK Activation Was Involved in the Protection of $R A$ against the Endothelial Dysfunction Induced by $\mathrm{H}_{2} \mathrm{O}_{2}$. AMPK is a crucial cellular energy sensor which senses change in the intracellular AMP/ATP ratio. It is also an intracellular stress sensor that is regulated by oxidative stress and other stresses that result in diminished cellular ATP levels. AMPK is one of the key modulators of eNOS in the endothelium and involved in the endothelial dysfunction induced by oxidative stress resulted from NADPH oxidase upregulation [20]. Here, we investigated the roles of AMPK in RA's protection to endothelial dysfunction induced by $\mathrm{H}_{2} \mathrm{O}_{2}$. As shown in Figure 4(a), compared with control, the response to ACh was similar to the AICAR- and RA-treated groups $(P<0.01)$. Similarly, activation of AMPK by AICAR decreased the NBT reduction. Whereas, the beneficial effect of RA on endothelium-dependent vasodilatation in rats was partly attenuated in the presence of compound C, a wellcharacterized AMPK inhibitor, reduced AMPK activity, and enhanced NBT reduction at $10 \mu \mathrm{M}$ (Figure 4(b)). Furthermore, when compound $\mathrm{C}$ was combined with $\mathrm{H}_{2} \mathrm{O}_{2}$, it intensified the NBT reduction. Mechanistically, we found that AMPK activated and increased the protection of RA on endothelial dysfunction (Figure 4(b)).

3.5. RA Treatment Improved Endothelial Dysfunction in HAEC via AMPK/eNOS Pathway. In order to further ascertain the relationship of AMPK and eNOS in the RA's effect, the AMPK-eNOS signal pathway activation was investigated by their phosphorylation in human aortic endothelial cells (HAEC) in vitro. As shown in Figure 5, the expression levels of total AMPK and eNOS remained unchanged. And the $50 \mu \mathrm{M}$ RA single treatment had no obvious effect on the AMPK and eNOS phosphorylation, while the $5 \mathrm{mM} \mathrm{H}_{2} \mathrm{O}_{2}$ treatment significantly downregulated the phosphorylation of AMPK and eNOS at Thr172 and Ser1177, respectively $(P<0.01)$, in HAEC cells. The cotreatment with RA significantly reversed the decrease of AMPK and eNOS phosphorylation induced by $\mathrm{H}_{2} \mathrm{O}_{2}$. The AMPK's inhibitor, compound $\mathrm{C}$ cotreatment, abolished the RA's upregulation of AMPK and eNOS phosphorylation in $\mathrm{H}_{2} \mathrm{O}_{2}$-treated HAEC cells. However, the AMPK agonist showed no more synergistic effect with RA. The results suggest that the AMPK phosphorylation played key roles in the protection effects of RA on $\mathrm{H}_{2} \mathrm{O}_{2}$-induced injury in HAEC.

\section{Discussion}

Endothelial dysfunction resulted from oxidative stress is the key initiating factor in almost all vascular events. Niethammer et al. found that the extracellular $\mathrm{H}_{2} \mathrm{O}_{2}$ generated by dual oxidase (Duox) reached $50 \mu \mathrm{M}$ after 20 min of wounding near the wound margin in zebrafish larvae, which constructed a concentration gradient and mediated the rapid 


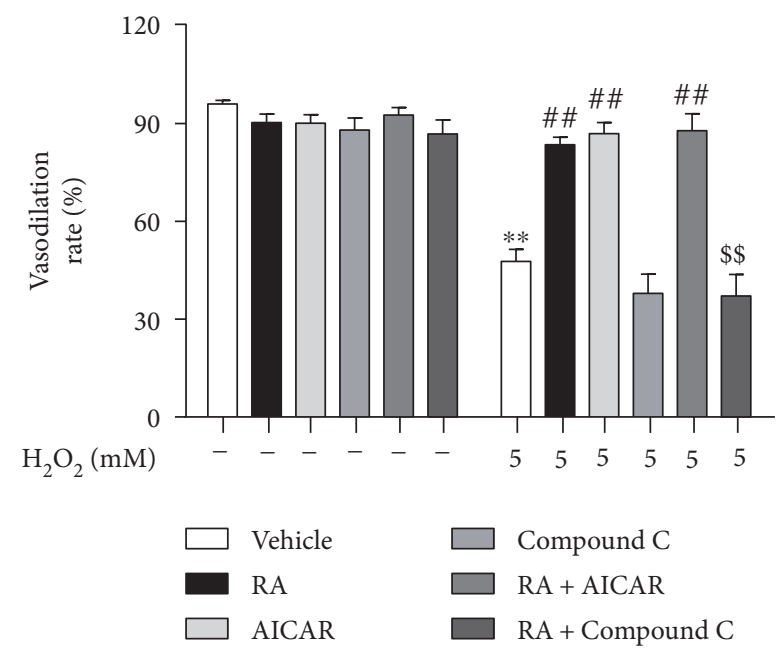

(a)

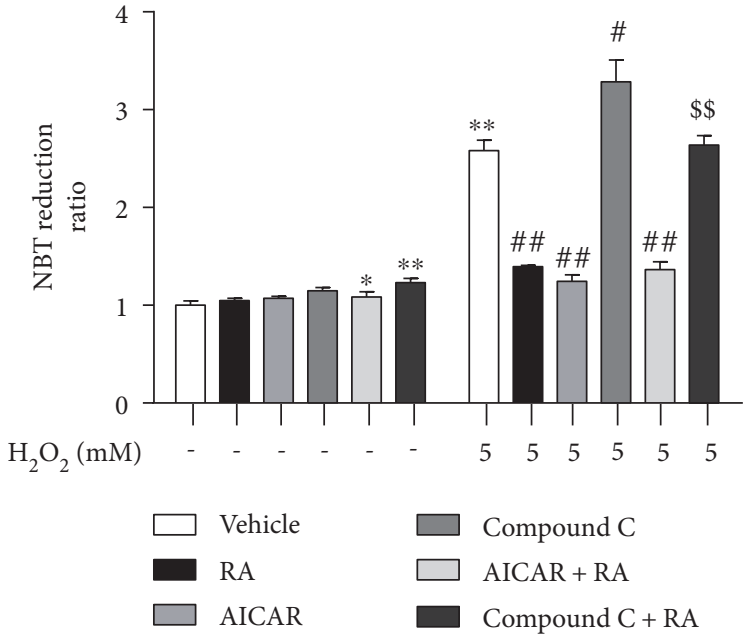

(b)

FIGURE 4: AMPK activation mediated the protection of rosmarinic acid against the endothelial dysfunction induced by $\mathrm{H}_{2} \mathrm{O}_{2}$ in rat aortic rings. The rat aortic rings were cotreated with AMPK activator AICAR $(50 \mu \mathrm{M}, 10 \mathrm{~min})$ or inhibitor compound $\mathrm{C}(10 \mu \mathrm{M})$ and $\mathrm{RA}$ $(50 \mu \mathrm{M})$ for $10 \mathrm{~min}$, then exposed to $\mathrm{H}_{2} \mathrm{O}_{2}(5.0 \mathrm{mM})$ for another $10 \mathrm{~min}$. The endothelial function was assessed by the endotheliumdependent vasodilation induced by acetylcholine $(\mathrm{ACh}, 10 \mu \mathrm{M})$. (a) The relative endothelium-dependent vasodilative rate after exposure to RA, AMPK modulator, and $\mathrm{H}_{2} \mathrm{O}_{2}$ in rat aortic rings. (b) The NBT reduction after exposure to RA, AMPK modulator, and $\mathrm{H}_{2} \mathrm{O}_{2}$ in rat aortic rings. Data are presented as the means $\pm \mathrm{SD}(n=6) .{ }^{*} P<0.05$ versus the untreated control group; ${ }^{* *} P<0.01$ versus the untreated control group; ${ }^{\# \#} P<0.01$ versus the $\mathrm{H}_{2} \mathrm{O}_{2}$-treated group; ${ }^{\$ \$} \mathrm{P}<0.01$ versus the $\mathrm{H}_{2} \mathrm{O}_{2}$ - and RA-cotreated groups.

recruitment of leukocytes to the wound [7]. Although the oxidative burst derived from the neutrophil activation in the inflammation will produce more ROS, there is no accurate concentration data of $\mathrm{H}_{2} \mathrm{O}_{2}$ reported. Here, we investigated the dose-effect relationship of $\mathrm{H}_{2} \mathrm{O}_{2}$ on the function of endothelium and vascular smooth muscle. In order to exclude the direct reaction of $\mathrm{H}_{2} \mathrm{O}_{2}$ with $\mathrm{PE}$ or $\mathrm{ACh}$, the aortic rings were incubated in fresh $\mathrm{K}-\mathrm{H}$ solution for 10 min and redepolarized with $\mathrm{KCl}$ after $\mathrm{H}_{2} \mathrm{O}_{2}$ pulse treatment for $10 \mathrm{~min}$. The results showed that the vascular smooth muscle reactivity to $\mathrm{PE}$ or $\mathrm{KCl}$ in endotheliumdenuded aortic rings were more vulnerable to $\mathrm{H}_{2} \mathrm{O}_{2}$ (at 5.0 and $10.0 \mathrm{mM}$ ) than in the endothelium-intact aortic rings (Figure 1), which indicated that the presence of endothelium protected the vascular smooth muscle from the oxidative injury induced by high concentration of $\mathrm{H}_{2} \mathrm{O}_{2}$. Moreover, the $2.5 \mathrm{mM} \mathrm{H}_{2} \mathrm{O}_{2}$ pretreatment resulted in the significant decrease of the vasodilative reaction to $\mathrm{ACh}$, which demonstrated that the endothelial cells were more sensitive to $\mathrm{H}_{2} \mathrm{O}_{2}$ than the vascular smooth muscle cells.

The previous work of Sotnikova et al. proved that RA significantly improved the endothelium-dependent vasodilation in diabetic rat aorta, which might be mediated by its antioxidative and anti-inflammation properties [8]. The present study proves that RA improves the impairments of endothelial-dependent vasodilation caused by $\mathrm{H}_{2} \mathrm{O}_{2}$ in normal rat aorta (Figure 2). NADPH oxidase is the major source of reactive oxygen species in endothelial cells and vascular smooth cells [21]. Besides, it has been proved that endothelial-dependent relaxation was effectively improved after the deletion of Nox2, which implicates that the endothelial dysfunction might be associated with Nox2 overexpression [22]. $\mathrm{H}_{2} \mathrm{O}_{2}$-induced endothelial-dependent relaxation impairment is associated with the increased production of superoxide anion $\left(\mathrm{O}_{2}^{--}\right)$. It has been proved that $\mathrm{H}_{2} \mathrm{O}_{2}$ could activate NADPH oxidase in a dose- and timedependent manner in respiration rate [23], and the oxidative injury to endothelium resulted from the excess ROS is the key mediator of endothelial impairment in atherosclerosis and diabetes [24]. Our work also proved that the pulse treatment with $\mathrm{H}_{2} \mathrm{O}_{2}$ significantly increased the NBT reduction in rat aorta and RA cotreatment significantly reversed the effects of $\mathrm{H}_{2} \mathrm{O}_{2}$, which demonstrates that the antioxidative activity is involved in the RA's protective effects on the endothelial function.

The endothelium-dependent vasodilation impairment is believed to be the consequence of a decreased bioavailability of nitric oxide (NO), an important endothelium-derived relaxing factor. The superoxide derived from NADPH oxidase could rapidly react with NO to form the stable peroxynitrite anion $\left(\mathrm{ONOO}^{-}\right)$, which will result in the decline of NO bioavailability. The other reason for NO signal dysfunction might lie in the eNOS expression and activation impairments. In our experiments, L-NAME partially decreased the phosphorylation of eNOS and antagonized the protective effects of RA on the endothelium dysfunction induced by $\mathrm{H}_{2} \mathrm{O}_{2}$, while it exacerbated the ROS formation in $\mathrm{H}_{2} \mathrm{O}_{2}-$ treated rat aorta. These results revealed that the effects of RA might be associated with the NO synthesis.

In the recent years, AMPK is demonstrated to improve vascular function by activating eNOS [25]. In addition to regulating energy metabolism, AMPK exerts anti-inflammatory and antioxidative activities [26, 27]. Previous studies indicated that AMPK activation improved the endothelial 


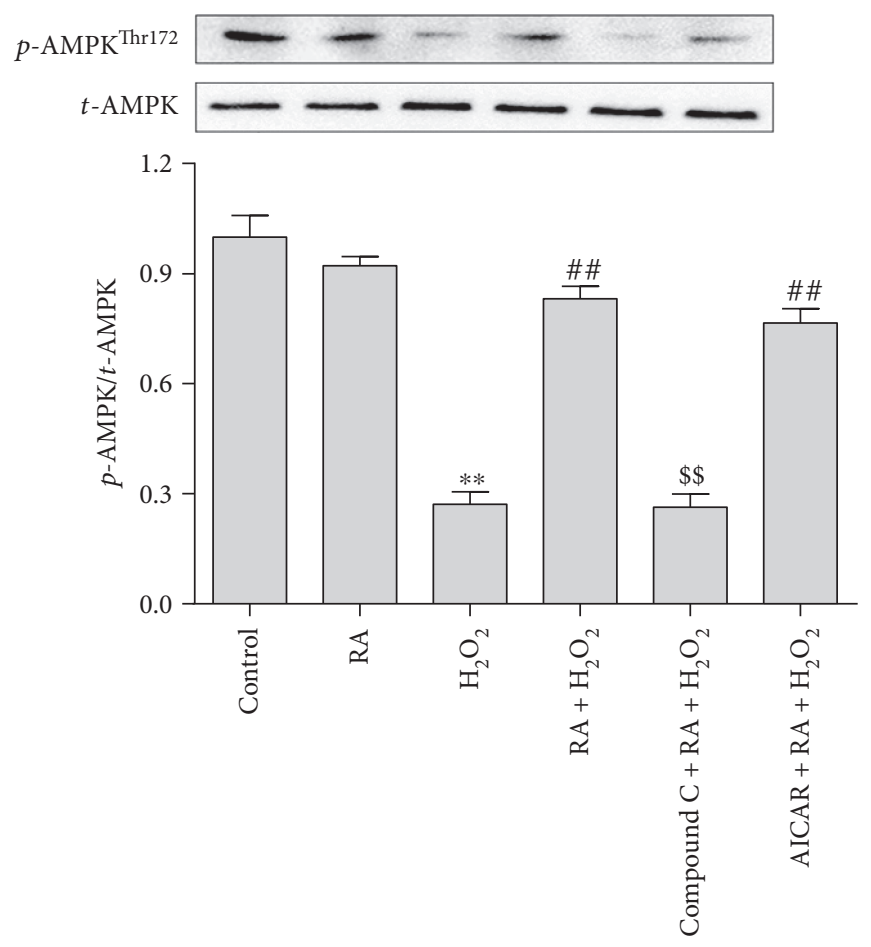

(a)
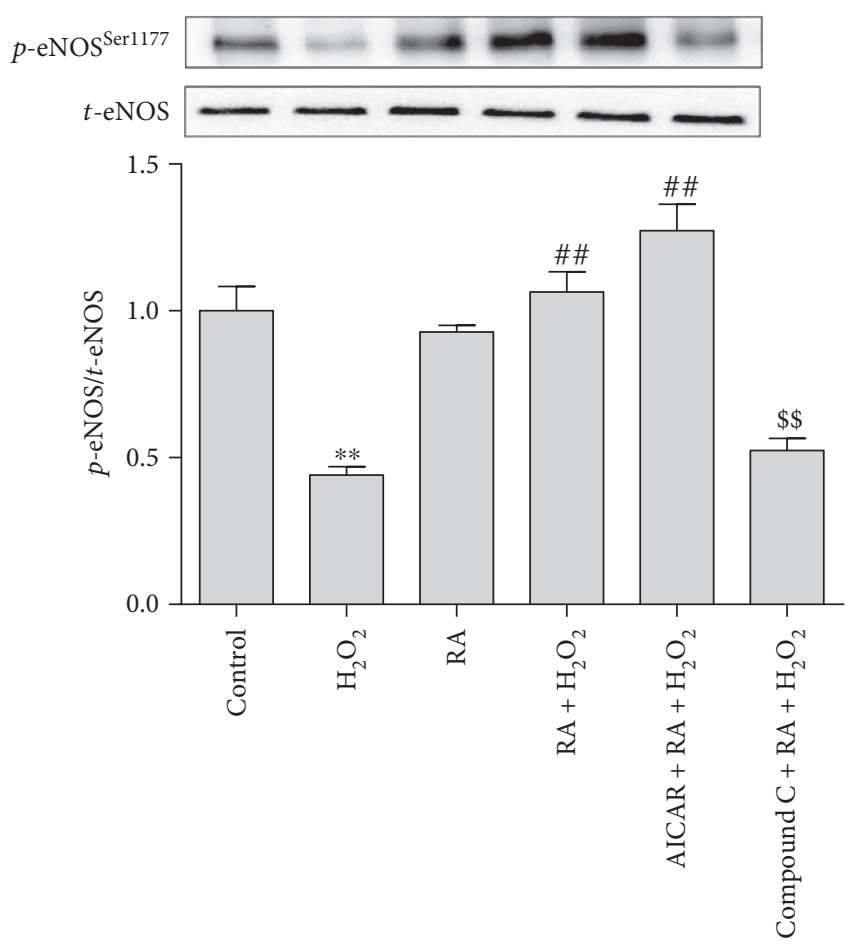

(b)

FIGURE 5: Rosmarinic acid induced the phosphorylation of AMPK and eNOS in HAEC cells. The HAEC cells were pretreated with the AMPK inhibitor compound $\mathrm{C}(10 \mu \mathrm{M})$ or activator AICAR $(50 \mu \mathrm{M})$ combined with RA $(50 \mu \mathrm{M})$ for 10 min prior to another 10 min exposure with $\mathrm{H}_{2} \mathrm{O}_{2}(5 \mathrm{mM})$. The total AMPK ( $t$-AMPK), phosphorylated AMPK at Thr172 site ( $p$-AMPK $\left.{ }^{\text {Thr172 }}\right)$, and the total eNOS $(t$-eNOS) and the phosphorylated eNOS at the Ser1177 site $\left(p\right.$-eNOS $\left.{ }^{\text {Ser1177 }}\right)$ were determined by Western blot. The results is quantified as the relative ratio of the phosphorylated protein/total protein. The values are presented as the means \pm SD; $n=3 .{ }^{* *} P<0.01$ versus the untreated control group; ${ }^{\# \#} \mathrm{P}<0.01$ versus the $\mathrm{H}_{2} \mathrm{O}_{2}$-treated group; ${ }^{\$} \mathrm{P}<0.01$ versus the $\mathrm{H}_{2} \mathrm{O}_{2}$ - and RA-cotreated groups.

function [28]. Here, we found that the AMPK agonist AICAR single treatment possessed the similar protective effects against endothelial dysfunction and oxidative stress induced by $\mathrm{H}_{2} \mathrm{O}_{2}$ in rat aorta as well as RA did, while the combination of RA and AICAR showed no further beneficial effect. The cotreatment with AMPK inhibitor compound $\mathrm{C}$ abolished the effects of RA, which further proved that the AMPK activation played a key role in the RA's effects. Hu et al.'s work revealed that $\mathrm{H}_{2} \mathrm{O}_{2}$ induced the bidirectional modulation in eNOS through the Akt and AMPK in a time- and dose-dependent way [29]. We also found that the Akt inhibitor LY294002 cotreatment significantly abrogates the RA's protection from the endothelium-dependent vasodilation impairments (Figure 1S available online at https://doi.org/ $10.1155 / 2017 / 7091904)$ induced by $\mathrm{H}_{2} \mathrm{O}_{2}$. And the RA significantly restored the phosphorylation downregulation at the Ser473 site of the Akt protein (Figure 2S). It indicated that the Akt signal pathway was involved in the RA's protective effects, while the interaction of AMPK and Akt in RA's effects needed to be investigated further.

In summary, this study demonstrated that RA significantly improved $\mathrm{H}_{2} \mathrm{O}_{2}$-induced endothelial dysfunction and the activation of AMPK-eNOS pathway was involved in the RA's effects. However, whether the modulating effects of RA is dependent on its direct activation of AMPK-eNOS pathway or its modulation on the oxidative status still remains unclarified in the present work. It needs further investigations to identify the underlying mechanisms of RA's protection on the endothelial function.
Abbreviations
RA:
Rosmarinic acid
K-H: Krebs-Henseleit
AICAR: $\quad 5$-Aminoimidazole-4-carboxamide-1- $\beta$-D-
PE. ribofuranoside
ACh: Acetylcholine
EC+: $\quad$ Endothelium-intact aortic rings
EC-: $\quad$ Endothelium-denuded aortic rings
L-NAME: NG-nitro-L-arginine methyl ester
eNOS: Endothelial nitric oxide synthase
I/R: $\quad$ Ischemia and reperfusion
HAEC: Human aortic endothelial cells.

\section{Conflicts of Interest}

No potential conflicts of interest were disclosed.

\section{Authors' Contributions}

Hui Zhou, Baocai Fu, Zhenhua Wang, and Ji Li designed and conducted the study. Hui Zhou, Bo Xu, Xiangquan Mi, Gang $\mathrm{Li}$, Chengjun $\mathrm{Ma}$, and Jianxin Xie collected the data and 
conducted the analysis. Hui Zhou, Bo Xu, Gang Li, Bo Xu, Chengjun Ma, Jianxin Xie, Zhenhua Wang, and Ji Li interpreted the data. Hui Zhou, Zhenhua Wang, and Ji Li wrote the manuscript. Hui Zhou and Baocai Fu contributed equally to this work.

\section{Acknowledgments}

This work is supported in part by the National Natural Science Foundation of China (21372190, 31470426), the Taishan Scholar Program of Shandong Province (tshw201502046), the "Personalized Medicines-Molecular Signature-based Drug Discovery and Development," the Strategic Priority Research Program of the Chinese Academy of Sciences (XDA12040320), and the Shuangbai Project of Yantai.

\section{References}

[1] C. R. Triggle and H. Ding, "A review of endothelial dysfunction in diabetes: a focus on the contribution of a dysfunctional eNOS," Journal of the American Society of Hypertension, vol. 4, no. 3, pp. 102-115, 2010.

[2] M. McIntyre, D. F. Bohr, and A. F. Dominiczak, "Endothelial function in hypertension," Hypertension, vol. 34, no. 4, pp. 539-545, 1999.

[3] P. Niethammer, C. Grabher, A. T. Look, and T. J. Mitchison, "A tissue-scale gradient of hydrogen peroxide mediates rapid wound detection in zebrafish," Nature, vol. 459, pp. 996-999, 2009.

[4] T. Heitzer, T. Schlinzig, K. Krohn, T. Meinertz, and T. Münzel, "Endothelial dysfunction, oxidative stress, and risk of cardiovascular events in patients with coronary artery disease," Circulation, vol. 104, no. 22, pp. 2673-2678, 2001.

[5] D. Giugliano, A. Ceriello, and G. Paolisso, "Oxidative stress and diabetic vascular complications," Diabetes Care, vol. 19, no. 3, pp. 257-267, 1995.

[6] Y. Higashi, K. Noma, M. Yoshizumi, and Y. Kihara, "Endothelial function and oxidative stress in cardiovascular diseases," Circulation Journal, vol. 73, no. 3, pp. 411-418, 2009.

[7] J. Davignon and P. Ganz, "Role of endothelial dysfunction in atherosclerosis," Circulation, vol. 109, no. 23, pp. III-27III-32, 2004.

[8] R. Sotnikova, L. Okruhlicova, J. Vlkovicova et al., "Rosmarinic acid administration attenuates diabetes-induced vascular dysfunction of the rat aorta," Journal of Pharmacy and Pharmacology, vol. 65, no. 5, pp. 713-723, 2013.

[9] U. Förstermann, "Nitric oxide and oxidative stress in vascular disease," Pflügers Archiv-European Journal of Physiology, vol. 459, no. 6, pp. 923-939, 2010.

[10] T. C. Travaglia, R. C. Berger, M. B. Luz et al., "Low-salt diet increases NO bioavailability and COX-2 vasoconstrictor prostanoid production in spontaneously hypertensive rats," Life Sciences, vol. 145, pp. 66-73, 2016.

[11] C. Xu, F. Tang, M. Lu et al., "Astragaloside IV improves the isoproterenol-induced vascular dysfunction via attenuating eNOS uncoupling-mediated oxidative stress and inhibiting ROS-NF- $\kappa$ B pathways," International Immunopharmacology, vol. 33, pp. 119-127, 2016.

[12] Z. Ungvari, N. Labinskyy, P. Mukhopadhyay et al., "Resveratrol attenuates mitochondrial oxidative stress in coronary arterial endothelial cells," American Journal of PhysiologyHeart and Circulatory Physiology, vol. 297, no. 5, pp. H1876H1881, 2009.

[13] R. Motterlini, R. Foresti, R. Bassi, and C. J. Green, "Curcumin, an antioxidant and anti-inflammatory agent, induces heme oxygenase- 1 and protects endothelial cells against oxidative stress," Free Radical Biology and Medicine, vol. 28, no. 8, pp. 1303-1312, 2000.

[14] E. J. Ruijters, A. R. Weseler, C. Kicken, G. R. Haenen, and A. Bast, "The flavanol (-)-epicatechin and its metabolites protect against oxidative stress in primary endothelial cells via a direct antioxidant effect," European Journal of Pharmacology, vol. 715, no. 1, pp. 147-153, 2013.

[15] M. A. Soobrattee, V. S. Neergheen, A. Luximon-Ramma, O. I. Aruoma, and T. Bahorun, "Phenolics as potential antioxidant therapeutic agents: mechanism and actions," Mutation Research/Fundamental and Molecular Mechanisms of Mutagenesis, vol. 579, no. 1-2, pp. 200-213, 2005.

[16] P. W. Peake, B. A. Pussell, P. Martyn, V. Timmermans, and J. A. Charlesworth, "The inhibitory effect of rosmarinic acid on complement involves the C5 convertase," International Journal of Immunopharmacology, vol. 13, no. 7, pp. 853-857, 1991.

[17] K. Kazama, K. Hoshino, T. Kodama, M. Okada, and H. Yamawaki, "Adipocytokine, progranulin, augments acetylcholine-induced nitric oxide-mediated relaxation through the increases of cGMP production in rat isolated mesenteric artery," Acta Physiologica, vol. 219, no. 4, pp. 781-789, 2017.

[18] M. Pourcyrous, C. W. Leffler, H. S. Bada, S. B. Korones, and D. W. Busua, "Brain superoxide anion generation in asphyxiated piglets and the effect of indomethacin at therapeutic dose," Pediatric Research, vol. 34, no. 3, pp. 366-369, 1993.

[19] M. L. Chang, J. S. Chang, W. Y. Yu et al., "Polygonum viviparum $\mathrm{L}$. induces vasorelaxation in the rat thoracic aorta via activation of nitric oxide synthase in endothelial cells," BMC Complementary and Alternative Medicine, vol. 14, no. 1, p. 150, 2014.

[20] A. E. Dikalova, M. C. Góngora, D. G. Harrison, J. D. Lambeth, S. Dikalov, and K. K. Griendling, "Upregulation of Nox1 in vascular smooth muscle leads to impaired endotheliumdependent relaxation via eNOS uncoupling," American Journal of Physiology-Heart and Circulatory Physiology, vol. 299, no. 3, pp. H673-H679, 2010.

[21] V. E. Edirimanne, C. W. Woo, Y. L. Siow, G. N. Pierce, J. Y. $\mathrm{Xie}$, and K. O, "Homocysteine stimulates NADPH oxidasemediated superoxide production leading to endothelial dysfunction in rats," Canadian Journal of Physiology and Pharmacology, vol. 85, no. 12, pp. 1236-1247, 2007.

[22] E. Shafique, W. C. Choy, Y. Liu et al., "Oxidative stress improves coronary endothelial function through activation of the pro-survival kinase AMPK," Aging (Albany New York), vol. 5, no. 7, pp. 515-530, 2013.

[23] E. A. Andronis, P. N. Moschou, I. Toumi, and K. A. RoubelakisAngelakis, "Peroxisomal polyamine oxidase and NADPHoxidase cross-talk for ROS homeostasis which affects respiration rate in Arabidopsis thaliana," Plant Polyamines in Stress and Development, vol. 5, p. 39, 2014.

[24] T. Mizuno, Y. Masuda, and K. Irie, "The Saccharomyces cerevisiae AMPK, Snf1, negatively regulates the Hog1 MAPK pathway in ER stress response," PLoS Genetics, vol. 11, no. 9, article e1005491, 2015. 
[25] Y. Zhang, T. S. Lee, E. M. Kolb et al., "AMP-activated protein kinase is involved in endothelial NO synthase activation in response to shear stress," Arteriosclerosis, Thrombosis, and Vascular Biology, vol. 26, pp. 1281-1287, 2006.

[26] S. Bijland, S. J. Mancini, and I. P. Salt, "Role of AMP-activated protein kinase in adipose tissue metabolism and inflammation," Clinical Science, vol. 124, no. 8, pp. 491-507, 2013.

[27] S. Schuhmacher, M. Foretz, M. Knorr et al., " $\alpha 1$ AMP-activated protein kinase preserves endothelial function during chronic angiotensin II treatment by limiting Nox2 upregulation," Arteriosclerosis, Thrombosis, and Vascular Biology, vol. 31, no. 3, pp. 560-566, 2011.

[28] H. Y. Tsai, C. P. Lin, P. H. Huang et al., "Coenzyme Q10 attenuates high glucose-induced endothelial progenitor cell dysfunction through AMP-activated protein kinase pathways," Journal of Diabetes Research, vol. 2016, Article ID 6384759, 14 pages, 2016.

[29] Z. Hu, J. Chen, Q. Wei, and Y. Xia, "Bidirectional actions of hydrogen peroxide on endothelial nitric-oxide synthase phosphorylation and function co-commitment and interplay of Akt and AMPK," Journal of Biological Chemistry, vol. 283, pp. 25256-25263, 2008. 


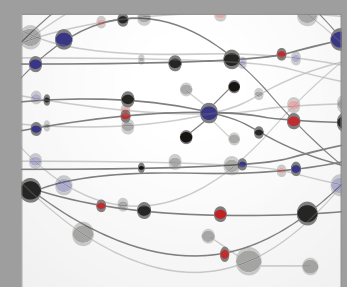

The Scientific World Journal
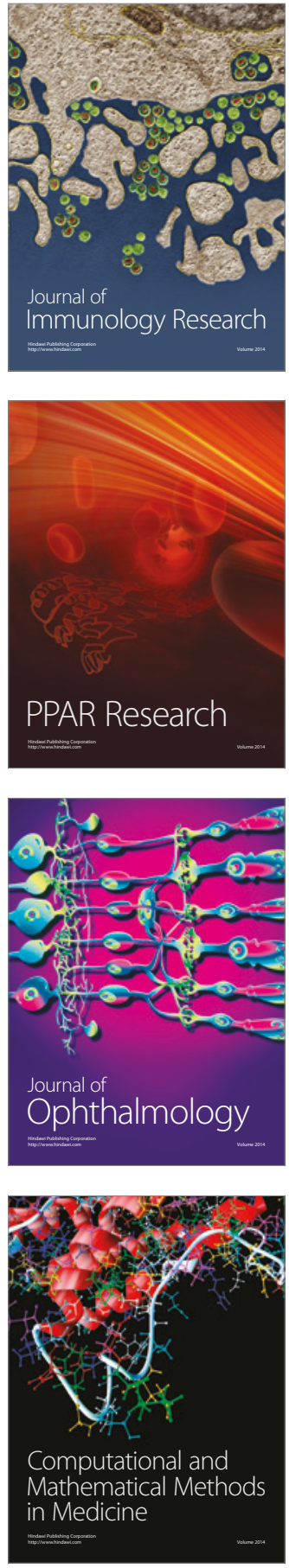

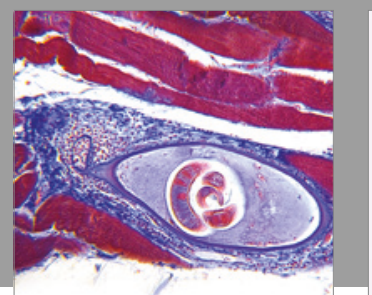

Gastroenterology Research and Practice
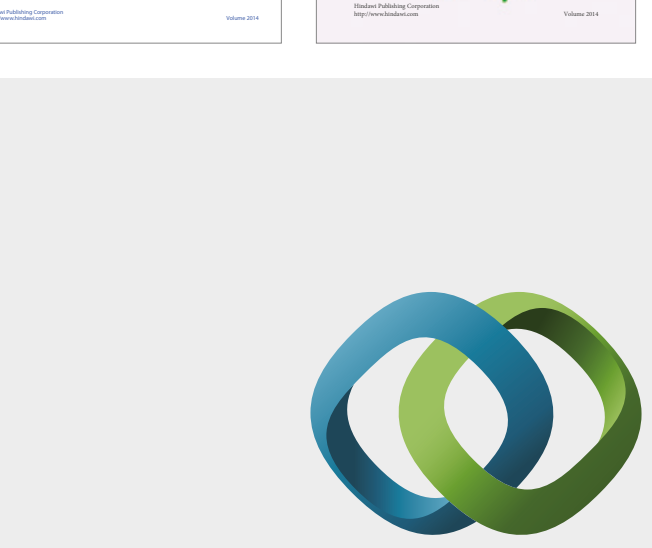

\section{Hindawi}

Submit your manuscripts at

https://www.hindawi.com
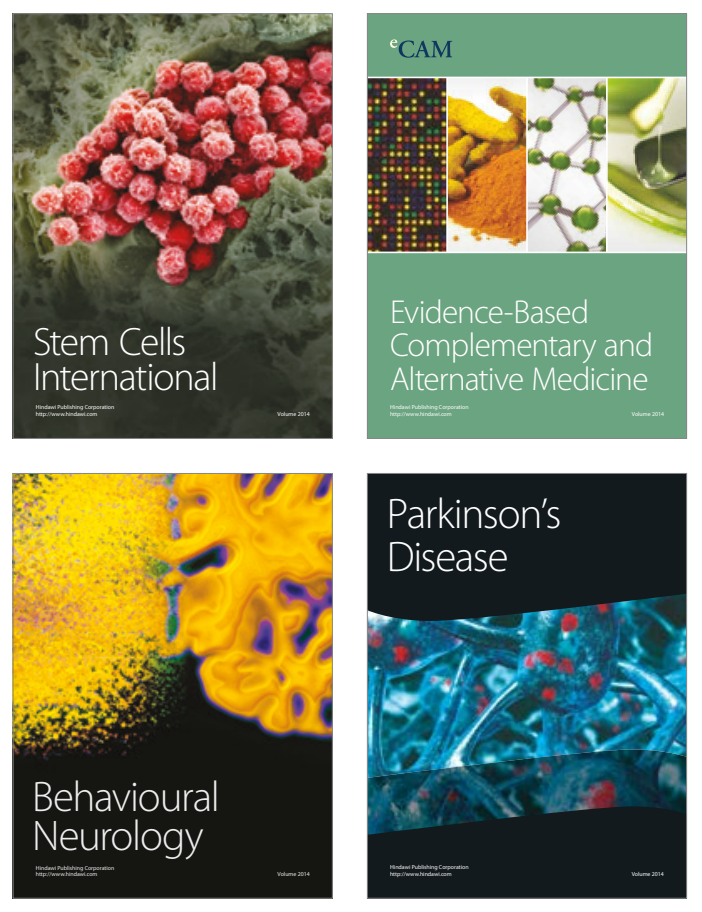
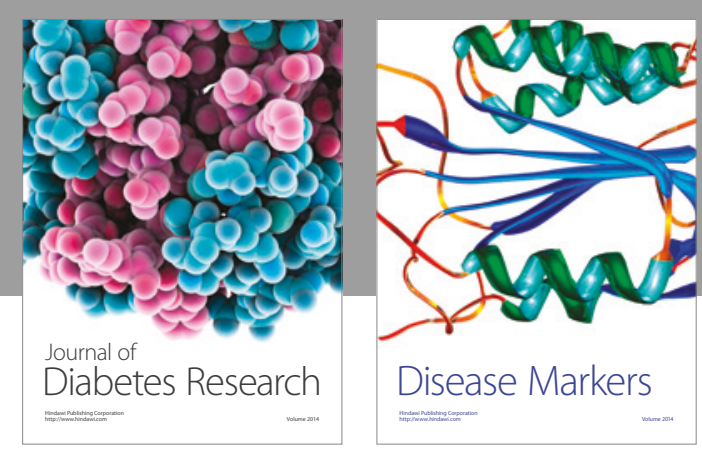

Disease Markers
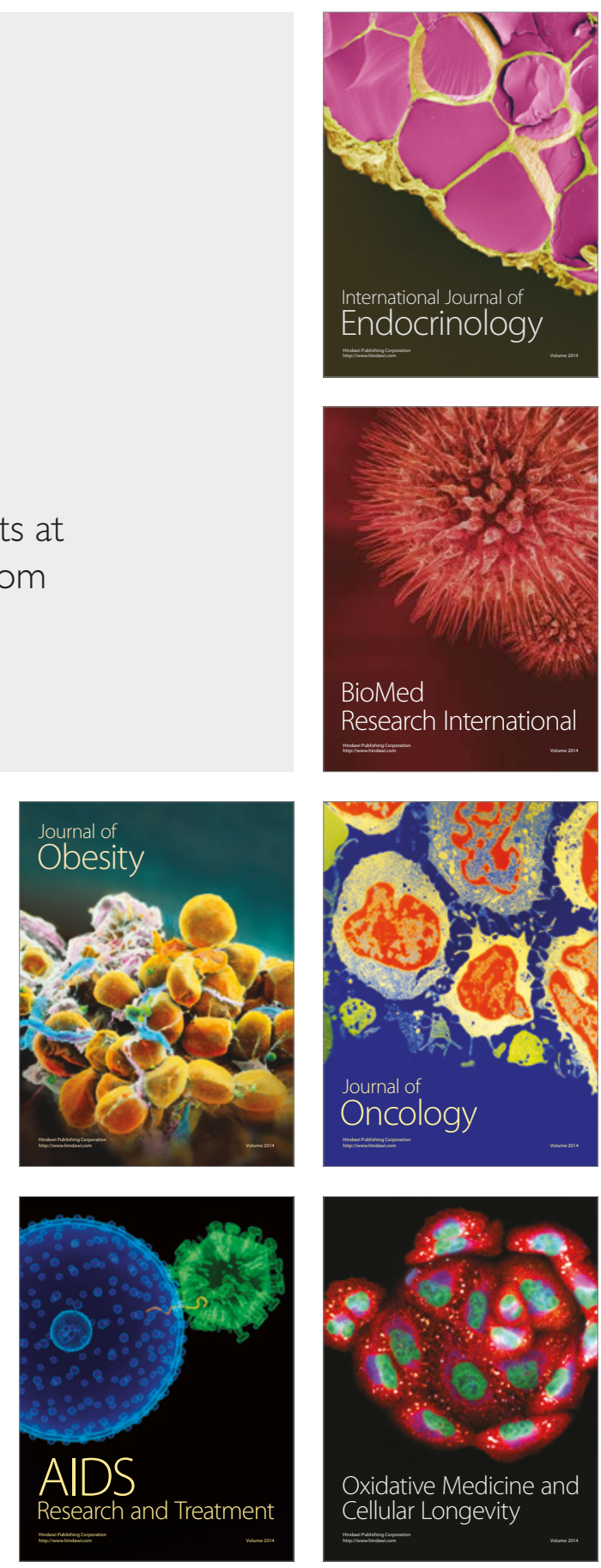